\title{
PERSPECTIVE
}

\section{Human capital in the digital economy}

\author{
Ashot A. Khachaturyan \\ Russian Academy of National Economy and Public Administration under the President of Russia, Moscow 119571, Russia
}

\section{Check for updates}

Correspondence to: Ashot A. Khachaturyan, Russian Academy of National Economy and Public Administration under the President of Russia, Moscow 119571, Russia; Email: glavred.uptp@mail.ru

Received: October 22, 2021;

Accepted: November 20, 2021;

Published: November 23, 2021

Citation: Khachaturyan AA. Human capital in the digital economy. Resour Environ Econ, 2021, 4(1): 314-324. https://doi.org/10.25082/REE.2022.01.002

Copyright: () 2021 Ashot A. Khachaturyan. This is an open access article distributed under the terms of the Creative Commons Attribution License, which permits unrestricted use, distribution, and reproduction in any medium, provided the original author and source are credited.

\begin{abstract}
The article analyzes the threats to human capital arising in connection with the development of the digital economy. The main problems, that digital can bring to public life and the fate of an individual worker are shown. According to the author, the labor market in the digital age makes new demands on the human capital of workers in almost all industries. The formation of a digital economic order, including automation, robotization and digitalization of almost all spheres of life, in the near future will leave on the labor market mostly "complex" professions of the "Knowledge" category with a creative component. Technological changes and the digitalization of the economy will lead to the fact that the knowledge and skills of workers will become so outdated that no retraining of them will be able to rectify the situation. One of the main problems is that with the further digital transformation of the economy, more and more jobs may be threatened with extinction, and the disappearance of old jobs this time will not be accompanied by the emergence of new ones. A situation may arise when the workers released due to digitalization will become not only unemployed, but generally not in demand by social production. A global question arises - what should they be kept for? Another problem is that with global digitalization, the danger of "digital" degradation of human intelligence is very high. Digital increasingly crowds out live communication, limiting the possibilities of developing a person's creative potential, as a result of which a qualitative transformation of human intelligence takes place. Another question arises - how to support the intellectual development of a person, and what to do with those who do not work?
\end{abstract}

Keywords: human capital, digital economy, creative economy, labor market, social threats, institutions of government and society

\section{Introduction}

Today, the leading countries of the world, in order to retain their leadership, are betting on the digitalization of the economy, which is based on the use of digital information and communication technologies that provide not only the replacement of production tools, but also the introduction of analytical systems that make production as profitable as possible. However, the risk that the consequences of the transition to the digital economy will not be as good for humans as expected is great. The fact is that the rapid rate of penetration of digital technologies into all spheres of life of modern society entails a change in the usual models of the economic and social structure of states. Digitalization also affects the person himself, transforming his worldview, changing values, culture of behavior and generational habits, methods of socialization and identification. Digitalization imposes new requirements on the competencies of a modern person and brings to the fore his ability to search for non-standard and creative solutions, forming new requests for the development of emotional intelligence.

Comprehension of the ongoing global changes associated with the development of digitalization of the economy, as well as various socio-economic consequences and its impact on various aspects of human life lags far behind the speed of the changes themselves. The problem is that today there is a rather "smeared" expert opinion that the development of the digital economy can bring fundamentally new things to the life of a person and society, we are just at the beginning of the path, at the beginning of comprehending what is happening in this area. Technological forecasts about the roadmap for the development of the digital economy are much more understandable, and there is much talk about this at the present time and quite definitely. Much less attention is paid to the problems that digital can bring to social life and the fate of an employee. That is why in this article we would like to talk not only about the digital economy, but also about the digital society, about the fact, that as a result of the use of modern digital technologies, a lot of new social phenomena, new processes and new difficulties appear. 
It seems to us that in addition to significant social and economic benefits, digitalization can bring a number of serious threats to society. The fact is that the accelerating digitalization of the economy poses new challenges for the state and society that they have not faced before. The biggest problem is that with the further digital transformation of the economy, the introduction of automation and robotization systems, the increase in labor productivity and the replacement of analog systems with digital ones, more and more jobs may become endangered. This can happen primarily because in the coming era of digitalization of the economy, the employee will compete with IT objects (robots, automatic machines, software packages, artificial intelligence) and inevitably lose, as a result, unemployment will become massive, the further socio-economic consequences of which are difficult to assess... The labor market will be hit hardest. The reason for this is new technologies.

\section{Problems of the future few labor market needs}

First, people will create digital manufacturing, and by creating it, they will, in essence, kill their own working position. And at the next stage, when they are fired because they are no longer needed, these people will need to go somewhere, and without the ability to find themselves in the future economy, they will not be able to cope.

Now there are 7 billion people in the world, of which about 3.5 billion are the working-age population over 15 years old. And jobs exist for only 1.2 billion. Digital technologies are being intensively introduced into all spheres of business and classic industries that have not changed for decades. It also affects the labor market: from a recent report by The World Economic Forum, it follows that in the near future robots will destroy more than 75 million jobs in the world. We are on the cusp of the largest unemployment in human history.

Indicative in this regard is the statement of the World Economic Forum (WEF) experts from the report "Digital Transformation Initiative": "the current estimates of (future) global job losses due to the digitalization process vary greatly, - from only 2 million to ... almost 2 billion by 2030 " [1]. One of the most radical long-term forecasts, for example, claims that the average unemployment rate worldwide will reach $75 \%$ by 2100 . As a moderate option with a short-term outlook, we cite the estimate given by WEF President Klaus Schwab: in his opinion, robotics and digital technologies will eliminate about 5 million jobs in 2020 in the 15 largest developed and developing countries of the world (which, in fact, is equivalent to only $1.25 \%$ of the total number of jobs in these countries) [2]. An increase by one unit in the number of robots per thousand employees in the industrial economy reduces wages in the country by $0.25-0.5 \%$ and reduces the economically active population by $0.18-0.34 \%$ - these are the calculations of D [3]. Acemoglu from the Massachusetts Institute of Technology and P. Respero of Yale University. According to them, now in the world there are from 1.17 million to 1.5 million industrial robots, the maximum is in the automotive industry (39\%), the production of electronics (19\%), metallurgy and chemistry (9\% each) [4].

On average, robots on the horizon of 20 years threaten to cut about $9 \%$ of workers, one new robot introduced in the world replaces 6.2 workers. Unlike previous periods, when job cuts were not so widespread, when laid-off workers had a chance to stay in the same enterprise (in the same organization), or at least in the same industry, now the reduction is more and more frequent and more often irreversible. The fact is that there will be fewer and fewer spheres of activity where a person can be more productive than a machine.

However, unlike in previous periods, when job cuts were not so widespread, when laid-off workers had a chance to stay in the same enterprise (in the same organization), or at least in the same industry, now the reduction is more and more frequent is irreversible. The fact is that there will be fewer and fewer spheres of activity where a person can be more productive than a machine. The main social threat of digitalization may be the emergence of a new phenomenon in society - e-unemployment due to the release of workers as a result of the digitalization of the economy and the emergence of a large number of "extra people" for whom it will be necessary to look for some kind of productive occupation and decide on the satisfaction of their household and social needs. Unlike previous periods of economic development, when job cuts were not so widespread, when laid-off workers had a chance to stay in the same enterprise or at least in the same industry, now the reduction will increasingly be irreversible. The most striking example of such an influence is the development of electronic taxi ordering services, which in large cities today have actually killed the profession of a taxi dispatcher. Other examples include the professions of a cashier, salesperson, librarian, typist, bookstore worker, and print-related activities. A very large number of people working in these areas already have no career prospects. The scale and speed of change is such that retired workers often have no alternative but to try to change their qualifications. Otherwise, a situation may arise when the workers released due to 
digitalization will not be able to work at all.

As history shows, human psychology is always one step behind what people themselves invent. So first the atomic bomb was created, and then the discussion of the ethics of its appearance began. The same is happening now, but with digital computer technologies. Morally, we turned out to be completely unprepared for the technological breakthrough that took place rapidly, the world around us changed dramatically, and the psychology of people and their paternalistic expectations from the state, by and large, remained the same. It may seem that in the short term it would be more profitable to freeze the situation: stability is almost always better and more comfortable than any revolutions, even technological ones. However, it is impossible to hold back technologies for a long time: they will reach us, if not in a year, then in 10-20 years [5].

\section{Personnel changes in the context of digitalization}

It will be difficult for everyone on the other side of digitalization. When a company adapts to new working conditions in the context of digitalization and robotization, because it cannot otherwise survive in the market, then it will first of all need employees who are also able to adapt No requirements will help an employee if he does not want to hear about Big Data, he is used to working the old fashioned way.

The decline in industrial employment has been taking place over the past several decades. In developed countries, the growth in the share of people employed in manufacturing stopped at the beginning of the 1960s. Previously it was called "the formation of a post-industrial society. "Now it is obvious that this is a deeper and more serious process. Previously, the decline in industrial jobs was offset by their growth in the service sector. However, job cuts are now being observed here as well. The development of neural networks, artificial intelligence technologies make it possible to completely abandon the presence of a person at the desktop. Many tasks that previously could only be performed by a person now take place without his participation. In addition, the emergence of industrial equipment, which does not provide for the availability of workers, has become a new challenge for workers. Only an operator is needed who will nominally control the production process.

Digitization is also radically transforming the service industry. In particular, in health care and social security, new opportunities are opening up for the timely prevention and early diagnosis of diseases, as well as for monitoring the condition of patients and people with chronic diseases. The development of genomic medicine and its convergence with ICT leads to the formation of a completely new direction - personalized medicine. Its unique properties are the ability to create individual treatment programs, built taking into account the characteristics of patients' DNA and a high degree of automation (for example, a genetic testing service), which allows it to function using e-business technology. Telemedicine, personalized medicine and healthcare information networks are changing traditional forms of healthcare organization and require special competencies for healthcare personnel.In recent years, "disruptive innovation" has come in a continuous stream: after the telephone was invented, the telegraph died; digital cameras have replaced film cameras; mobile phones have made wired phones, calculators, and cheap cameras useless. The social consequences of the introduction of new technologies were sometimes severe, but in the past there was always a new job for those who lost their jobs. Peasants went to work in factories, grooms went to gas stations, typists found something in the same office.

Now everyone should understand that such concepts as "profession", "stable employment", "career" in the classical sense of the word, no longer exist and never will be. Moreover, it does not depend on the qualifications of the employee. There are examples when a former private security guard became a system administrator, completely and radically changing the profile of his activity. And there are examples when investment bankers have been out of work for years, because now there are practically no investment banks left, but they continue to hope for a miracle.

The looming situation in society promises to be problematic for two reasons. First, new technologies are advancing simultaneously on many fronts. Robotic checkout counters can be seen in many stores; auto-driving cars are already driving on normal roads. Let us assume as a possibility that these two technologies will be perfected to a certain degree and spread. What will happen? Many millions of drivers and cashiers will be left without work. News is coming regularly today of new robots making applications for human jobs. Many banks fire accountants and lawyers en masse. Enterprises and organizations are getting rid of personnel officers and transferring the functions of recruiting and managing personnel to robots. There are already robotic surgeons that are able to independently perform operations on living patients (although they still need a team of assistant operators). There are many such examples today.

Big data is already being effectively used in Internet companies, banks, telecommunications 
and e-commerce; soon they will be actively used for information analysis and in medicine. In banks, for example, robotic programs are already engaged in trading. Labor market trends will not be driven by digitalization as such, but by people who will be able to use the opportunities of digitalization to achieve the desired results. Therefore, now in the global labor market there are opposite trends, which do not contradict each other, however, - a decrease in demand for labor, while competition for universal and highly professional "digital" specialists is growing.

\section{Disappearance of old jobs}

A thousand horses created jobs for a thousand coachmen, a thousand cars for a thousand drivers. A thousand self-driving cars will not need chauffeurs at all; a thousand jobs will simply disappear. Information technology is very scalable. A hairdresser can cut 20 people a day, and a programmer can make a program that will be used by 20 million people every day [6]. Because of this, it will not work to retrain all the unemployed as programmers: the planet does not need so many programmers.

Already, there is an active decline in employment in the industrial sector, the globalization of the labor market and tougher competition, a sharp increase in people employed in remote work. The digitalization of agriculture is actively developing. These include improving logistics, intelligent irrigation, soil and crop monitoring (including systems for recognizing plant diseases), smart technology (equipped with sensors, sensors, etc.). Changes in the labor market in agriculture will be comparable to what we've seen before in this industry, where more than 80 percent of the population was employed not so long ago [7]. They will happen in a shorter time, but will be comparable in scale. New industries will be very sparsely populated, just like agriculture, where four to five to six percent of the people work today. And the requirements for these people will be incredibly high.

Unmanned tractors are not yet working in the fields, but their projects are already in the testing stage. Case 1 made the farthest advance in this direction, introducing the Autonomous Concept Vehicle in 2016, and the Case IH Magnum unmanned tractor in the summer of 2017 (together with $\mathrm{CNH}$ Industrial). The introduction of unmanned tractors and combine harvesters will increase the production cycle from 8-10 hours to 24 hours, because unmanned agricultural machines do not get tired and are not limited in their functioning during the daytime.

All global car manufacturers are actively participating in the race to create unmanned vehicles, a legal framework is being developed for this, there are even projects to ban human driving in urban conditions by 2025. The introduction of unmanned vehicles into everyday life will lead to the displacement by automatic machines and artificial intelligence of up to $100 \%$ of workers in such professions as: "truck driver"; a driver engaged in cargo transportation within the city; Bus driver; taxi driver; agricultural machinery driver; heavy mining truck driver.

The second branch is construction, including roads. Today we can say with confidence that the son of a bricklayer will never again wield a trowel. This specialty was sentenced to death (albeit with a deferred execution) after the brick stacking robots were created. For example, the Australian machine Hadrian X stacks 1000 bricks per hour. That's 8-10 times more than a flesh-and-blood builder is capable of stacking.

Construction has long been the most conservative industry. Everywhere labor productivity grew, while in construction, on the contrary, it fell. But now the situation is changing here too. Two technologies that have become widespread in recent years have already profoundly changed the way businesses do business in the industry. These are prefabrication (and related 3D printing) and building information modeling. Prefabrication allows you to quickly assemble any building from finished parts, like a constructor. Parts can be made both in a precast concrete factory and printed on a 3D printer.Digital modeling allows you to find errors of architects at the stage of the project, significantly save time, resources and labor.

In Mexico, New Story teamed up with Icon and Echale to build the world's first D-printed village. The walls of the houses are erected using an Icon Vulcan II 3D printer, which squeezes the cement out of a nozzle layer by layer. The process takes about 24 hours per house. The construction of the roof, the installation of doors and windows, and the interior decoration are already carried out by teams of builders. The one-storey buildings are divided into two bedrooms, a living room, a kitchen and a bathroom. They are supplied with electricity and running water. Two houses have already been built. The remaining 48 houses are expected to be inhabited in 2020.

According to the forecast of the international construction and development company Balfour Beatty, by 2050 robots that will erect complex structures using dynamic materials will displace people from the construction industry. Drones will scan a construction site, analyze data and solve problems before they arise, they will give instructions to robotic equipment. A person 
will have the role of a remote supervisor-manager of several projects at once - for this he will have an array of data, 3D and 4D images. A few people on the construction site will work in exoskeletons with neural control, they can easily move construction equipment. The staff of service personnel will be reduced, and the competence of specialists will grow, as a result, the decision-making process will become much faster and easier.It is the construction companies and the auto industry that will soon have to either adapt to the changes as quickly as possible, or accept the inevitable and leave the market forever. As well as everyone who is not ready to change today. The choice is only for the leaders.

The Russian economy, for example, currently employs about 72 million people. The first place in terms of the number of people employed over the past 15 years is the profession of a driver, which is 5 million Russians, or $7 \%$ of the employed. The second -4.9 million sellers (6.8\% of employees). Thus, only these two professions promise Russia in the near future the release of up to 10 million people as a result of digitalization. And this process has already begun - in many stores in Moscow, for example, there are already cash terminals, where there are no sellers and buyers serve themselves. It should be noted that these same professions are among the most representative in most countries of the world. In general, we are talking about the fact that in Russia, within about 10 years of work, one third of the population employed in the economy may lose. The worsening demographic situation compensates for only 1.5 million of them. For the rest, the problem of employment will become acute, and if the authorities do not have time to prepare, then soon they will face a difficult choice: to admit a social crisis or to stop development from "social" considerations.

The development of technologies, the digital transformation of companies, the growth of competition for jobs, and an increase in life expectancy will force workers to change their professional activity several times during their life, acquiring new competencies and skills. To remain in demand in the labor market, a person will have to acquire new knowledge faster than it was before. The very concept of a profession is being transformed, since the set of competencies that an employee who has received training in a particular profession or specialty should possess ceases to be fixed, static; competency profiles become changeable, they are modified following technological and organizational changes, they turn into "dynamic portfolios".

\section{Disappearance of many professions}

Moreover, the list of "disappearing" professions is replenished by those, that previously seemed eternal. A few decades ago, one could say that a person could get an education and a profession and live and work with them happily throughout his life. However, today the speed of technology change is such that the relevance of the education received has become very limited in time. In the near future, almost every profession that exists today can either disappear altogether, or change significantly.

Structural unemployment will be a big problem in the near term. Many analysts predict its widespread character, especially among people without education or with secondary specialized education. Changes in employment due to the widespread introduction of automation will affect, first of all, workers with average qualifications, since their functionality contains a sufficient number of template functions so that they can be automated, and these specialists are highly paid enough to make automation economically feasible.

Automation in industries always starts with jobs of an average skill level.These jobs contain enough boilerplate components to be easily automated, and high-paying enough to make automation economically attractive to business owners. Therefore, the main blow from robotization will fall on the "intellectual" middle class, that is, people who are engaged in work requiring intermediate qualifications - engineers, service personnel, the working class. In the very near future, society will no longer need people of average qualifications. The need for mass education of the middle level, which arose during the period of industrialization, will also disappear algorithms will cope better with many not only routine, but also intellectual operations. At the same time, the need for cooks and hairdressers will never disappear. The social consequences of such automation will lead to an unlimited increase in the number of people that society can feed but cannot occupy. Psychologically, this will create an extremely uncomfortable living environment for humanity as a whole.

Previously, a person dreamed that robots would work hard, that they would get the rough and dangerous work. But in fact, it turns out that artificial intelligence is pushing a person out of areas that are considered intellectual: lawyers, accountants, recruiters already mentioned, and so on. It turns out that either a low-skilled sector remains for a person, or, conversely, a very highly qualified job. And this stratification is happening all over the world.

There are now about 70 million engineers in the world. It is known, that 80 percent of their 
work consists of searching for analogs on the Internet and minor revision of existing solutions. And only 20 percent of the product of the activity of design engineers is new developments [8]. Studies show that only a small part of the people from this multimillion army are able to retrain and find new applications in the face of competition with robotization. The problem is not even that hundreds of millions (if not billions) of people will lose their jobs for a while.

Nevertheless, the main thing in the digital economy will still remain the person. One way or another, he will have to support and develop digital processes. This will require a lot of highly skilled workforce. In the process of digitalization, the line between different businesses will be blurred, which will lead to global competition for labor resources between the industries of the new digital economy. In the digital age, the difference in the struggle for personnel between, for example, an engineering company and a bank will practically disappear. Because both there and there you will need approximately the same people who will be able to modernize these industries, solve problems, create new models and business processes, process and analyze data.

The transition to a digital economy is fundamentally changing the labor market: along with the spread of information technology in all spheres of life, digital skills are becoming critically important from the point of view of employers. A massive transformation in talent requirements is expected, as many operations that have not been affected by previous waves of digital adoption may be automated in the near future.

When hiring personnel, priority will be given to candidates who are guided by the acquisition of new knowledge and skills, strive to be in the "trend" of the products of the technological revolution, and are not guided only by the traditional training model with a narrow specialization. There is only one conclusion from all this - mass unemployment, unfortunately, is inevitable. And it can cover the world community much earlier than skeptics now suggest. Many experts believe that robotization will begin to destroy jobs on a massive scale in the next three to five years.

Creative thinking is a process, first of all, the process of generating ideas. Therefore, the competence "creative thinking" means having the ability to generate ideas". Generation itself is not an end in itself for any business, therefore, creative thinking also exists at the interface with other competencies: critical thinking (the ability to evaluate ideas), collaboration (the ability to come up with a team), imaginative thinking (the ability to visualize ideas), etc.

Creativity as a competence is becoming more and more in demand as simple everyday work is performed by robots. A person devotes more time to complex tasks to create new technologies, products, entertainment. Non-standard situations, rapidly changing environments require quick creative solutions. The development of creativity is a massive trend.

\section{Creative class changes the future}

Creativity is both an innate ability and the result of upbringing, education and life experience. The more creative is present in a person's life, the more creative he becomes. Of course, there are people who are more inclined to creativity and creativity, so to speak, have talent. They need inspiration, and people with a technical / logical mindset need ways to develop creativity. There are already whole schools that study the phenomenon of creativity and high-quality higher educational institutions that teach knowledge and skills for the development of creativity. The experience of their work suggests that flexibility of thinking develops through training, and with sufficient perseverance, you can learn to go beyond the framework of stereotyped thinking in a short time.

Today, nonlinearity and creativity of thinking, skills of working with various platforms, formats and large flows of information, the ability to isolate what is necessary, which generates a multi-channel assimilation and transmission of information, are becoming a key personality trait. All these requirements for skills and competencies create the basis for the development of increased individual responsibility (especially due to the transparency of all digital processes), the desire to learn new language features, the development of cognitive abilities, the development of distance communication skills, critical thinking and digital literacy. In this regard, a new attitude towards a person is being developed today, a person of individualized decisions comes to the fore, and not a person of mass labor, as it was before [9]. Therefore, in order to create an environment for the development of a digital society in modern conditions, it is no longer enough just to increase the basic digital literacy of society as a whole, but it is necessary to adapt the entire educational infrastructure to new requirements.

The situation requires many people to retrain, get a second higher education and, in general, not sit on an equal footing. Therefore, the key skill now is constant self-education and obtaining new competencies, creating a flexible set of them that allows you to adapt to any changes. The imperative of the future emerging today is the free labor of a creative worker, i.e. the labor of a 
person who freely chooses the sphere of his activity and self-realization and is free (not subject to either material factors of production or external control from capital and bureaucracy) in the labor process.

Creativity (the ability to generate new ideas and concepts) is considered the most important competence of an employee employed in the digital economy. However, a society in which most people are engaged only in the production of ideas is unstable. For theories and inventions to be useful, they must be put into practice. This should also be done by creative people, who perceive new ideas and copy them. What should be the optimal ratio of creative workers and workers who reproduce their ideas in the creative economy? According to experts, to maintain balance in the creative class, there should be no more than 30 percent of creative workers engaged in the production of ideas. The remaining 70 percent of the creative class should be engaged in copying (that is, putting into practice) the concepts created.

During the 20th century, the creative class has grown more than tenfold, from three million to today's level; since 1980 alone, its numbers have more than doubled. Many states are now intensively building up their "creative class", as it is the locomotive for overall economic growth. In the United States, the creative class outnumbers the traditional working class, which includes those who work in manufacturing, construction or transportation, about 38 million people, $30 \%$ of all working Americans belong to this class. In Singapore, there are more than $50 \%$ of such people at the moment.In European countries with developed economies, for example, in Great Britain, there has long been a list of professions related to the creative industry, and together in these areas about $40-42 \%$ of the population is employed.

The core of the creative class consists of people engaged in creative work in science and technology, architecture, design, education, art, music and entertainment, whose economic function is to create new ideas, new technologies and new creative content. In addition to this central group, the creative class includes "creatives" across a range of knowledge-based industries such as the high-tech sector, finance, law and healthcare, and business administration. These people are involved in materializing the ideas of super creative creators. They can also test and develop new technologies, treatment protocols or management methods, and develop them. These people are engaged in solving complex problems, which requires significant independence of thought and a high level of education and human capital.

\section{Radical difference between creative and other classes}

The working class and the service class are paid primarily to get the job done according to plan, while the creative class makes money by designing and creating something new, and does so with more autonomy and flexibility than the other two classes. Creativity presupposes certain types of thinking and character, that must be cultivated both at the individual level and in the society that surrounds a person. Accordingly, the creative ethos permeates everywhere, from professional culture to universal human values and communities, changing our understanding of ourselves as economic and social subjects, i.e., identity itself. It reflects norms and values that both fuel creativity and help strengthen its role. Moreover, creativity needs a supportive environment that provides a range of incentives - social, cultural and economic. Therefore, it is directly related to the development of new working conditions, lifestyles, forms of communication between people and neighboring communities, which, in turn, contribute to creative activity. This kind of atmosphere is critical to technology creativity and the commercial innovation and wealth that depends on it.

According to the expert opinion of psychologists and sociologists, the natural rate of birth of "active", leaders more predisposed to creativity and creativity (so to speak, have talent) is within $10 \%$ of the total population to $90 \%$ "passive" in any society. Creative leaders always make up only about $5 \%$ of the total number of any stable group. They are the basis of the super-creative core of the creative class, the real creators of the future. The remaining $90 \%$ of society is a passive majority that does not have outstanding qualities, is unstable in its moods, following the active ones, adhering to one of the above-mentioned groups, depending on the pressure of the material conditions of their life.

Although creativity is considered to be a purely personal phenomenon, it is nevertheless an integral part of the social process. Creativity thrives most in a unique social environment - an environment that is stable enough for continuous work, but which also has a variety and breadth of thought that stimulates creativity in all its provocative forms. There are four key characteristics of the time and place where creativity thrives best: professional occupation, intellectual sensitivity, ethnic diversity, and political openness. The digitalization of the economy and the subsequent release of workers pose two main questions for the state and society: How to occupy the released workers, and How to provide material and monetary conditions for their 
survival?

As a result of automation, robotization and digitalization of the economy, a special social stratum of society has arisen - the precariat, i.e. low-security stratum of the population - young people, the elderly, disabled people, the disabled, migrants. Precarious is a term coined by Pierre Bourdieu and derived from the English word precarious, which means "unstable, unreliable, threatening" [10]. This term denotes a class whose members do not have a "normal" job, which would be characterized by permanent employment, stable earnings and social guarantees provided by the employer and the state. Below the precariat there are only the poor, lumpenized people living and dying on the streets without any connection with society. The middle class, which peaked in the 1970s, is slowly but surely sinking into what it is today.

This new class is quickly turning into a threat and a fundamentally new challenge for the entire modern world due to the fact that the people of the precariat are especially characteristic of: constant dissatisfaction with their position and life in general; loss of reference points in everyday existence; anxiety and alienation from society. The main characteristic of the representatives of this class is the status of "permanently" temporarily employed. These people can become unemployed at any time. The lack of regular income or stable earnings makes their situation chronically precarious. And there are already all the preconditions for the evolution of the proletariat into a precariat to continue in the near future and the latter will become an "unnecessary". At the initial stages of the digital revolution, the precariat are people constantly engaged in temporary work. Robotization and the introduction of artificial intelligence will gradually make it simply unnecessary for the digital economy. To the extent that the invention of the internal combustion engine made horses unnecessary in the early twentieth century. A specific and very dangerous phenomenon has already formed - on the basis of the precariat a "militarized lumpen" has arisen, which does not want (and can no longer!) Return to peaceful daily work. He is interested in whipping up and inciting conflicts, because participation in the conflict, like enrichment from robbery in the territories of hostilities, is his earnings and way of existence [11].

The precariat has three characteristics. First, they have no job security, job security. Second, the precariat cannot count on pensions, unemployment benefits, or medical bills. And thirdly, the precariat has a special relationship with the state: more and more people in the precariat do not have the same rights (civil, social, political, cultural and economic) that other citizens have. To solve all these problems, Guy Standing, as the ideologist of the "precariat society", proposes the idea of "unconditional basic income" - according to it, every citizen, regardless of merit to the economy, periodically receives a fixed amount to meet basic vital needs [12]. To get everything else, he is invited to earn. The costs in this case should be covered, for example, by excess profits from the sale of natural resources.

\section{New large class of useless people}

What will they do: organize revolutions? Breaking robots like the Luddites used to destroy cars? According to a study by Eric Hirst, an economist at the University of Chicago, 22 percent of young American men with no college degrees (roughly 20 million) have not worked a day in the past year. At the same time, 7 million of the unemployed did not even attempt to find a job. What are these young guys doing? According to research, they spend little time on the street, live with their parents and have no intention of getting married. It turns out that they play video games most of their leisure time! Over the past 15 years, the amount of free time for young men under the age of 20 has increased by 4 hours per week. 75 percent of this is spent on toys. In absolute terms, on average, young unemployed guys spend 2 hours a day in virtual reality. But at the same time, 10 percent of those surveyed said that they play at least 6 hours a day. What means will the representatives of the "useless class" live on? Now, according to Hirst, most of the "extra" young people live at the expense of their parents. In 2014, 70 percent of them sat on the neck of relatives. For comparison, in 2000 - only 35\% "milked" mom and dad. To mitigate possible social threats from the precariat, fundamentally new issues of creating and distributing national income related to the release of workers as a result of digitalization have already begun to be discussed. In particular, the issues of building a special "compensation mechanism" for them, incl. the possibility of introducing a universal payment, when a citizen of the country will receive a minimum income, regardless of his labor contribution. Another very important result of digitalization arises when it turns out that free time in society is no less important than working time.

One of the economic solutions to maintain the personnel released as a result of digitalization processes is seen by many in the organization of payments to such people as a kind of "unconditional income" - money received by them regardless of any conditions or circumstances, simply 
by the fact of citizenship (or residence) in the territory of the given country. It is widely believed that in the event of mass technological unemployment, the introduction of "unconditional basic income" can become a socially justified replacement for the lost wages as a result of the release. Last year, Switzerland held a referendum on the introduction of such income, which would be paid to every citizen of this country. But it failed - the citizens feared that it would become a bait for migrants. However, 6 countries have already decided on local experiments with this system. Canada, Finland and Holland are planning to distribute such money to citizens (from 700 to 1400 dollars per month).So they will provide bread and butter to useless people. It will be much more difficult for them to come to terms with the meaninglessness of their existence.

The coronavirus pandemic in early 2020 has become a kind of tough "training" for the governments of many countries in choosing measures to provide social assistance to the population due to rising unemployment. For example, in the United States, as a result of the crisis that has arisen, according to analysts' estimates, 37 million Americans may lose their jobs - most of all jobs will be cut in restaurant activities (about 9 million people), education (3.2 million jobs) and retail (2, 8 million). Before this crisis, unemployment in the United States was about 3.5\%, but if it reaches the expected $20 \%$ as a result of the crisis, this will become the worst indicator since the Great Depression that hit the country in the 30s of the last century. Today, a third of American entrepreneurs are confident that under the current conditions they will not be able to hold out for more than three months before they are forced to go out of business, winding up their businesses and laying off employees. Analysts at American recruiting agencies have compiled a list of the most "vulnerable" vacancies, which is headed by cashiers, waiters, cooks and gardeners.

Quarantined people need a lot of government support. In this regard, the main trend in the 2021 season was direct payments from the state budget in the form of unconditional income to those who temporarily lost the opportunity to earn. Of the $\$ 2.2$ trillion US government anti-crisis package provided for this purpose, a quarter went to direct payments to the population. The massive package included a $\$ 500$ billion fund that was used to support the hardest hit industries, as well as direct payments to millions of American families. The set of support measures included the allocation of direct financial assistance to citizens in the amount of $\$$ 1,200 for those whose income is below $\$ 75$ thousand per year, $\$ 2,400$ for families with a total income of less than $\$ 150$ thousand per year, and the payment for a child will be $\$ 500$. It also provided for the expansion of unemployment benefits ( $\$ 600$ per week will be added to their usual amount) and the expansion of unemployment insurance ( $\$ 260$ billion will be allocated for this purpose). It was assumed, that the cash allowance would make it easier for people in quarantine to buy food, pay for utility bills and bank loans, and this would reduce risks for the financial system. Naturally, in connection with this campaign, the question arises - how possible is such a scenario of "helicopter money" not only in a pandemic, but also in the event of a massive layoff of workers due to digitalization?

Most likely, the digital economy of the future will no longer need cheap human labor and the process of laying off workers will continue. This means that the question of their content after release will always be relevant. In addition, another social problem will be added to this question - how can these people be occupied (socially useful)? That is why today the introduction of a unified social payment is being seriously discussed at a referendum in Switzerland. German Chancellor Angela Merkel also suggests, thinking about how much and who will have to pay for voluntary idleness. In Finland and Sweden, unemployment benefits are often higher than official wages. In Holland, the huge taxes of socially responsible citizens, almost half of their earnings, make their high income meaningless - it's easier to do nothing at all. Of course, exclusive specialists will always be in demand. But in general, it may turn out that by the middle of the 21 st century, most European countries will be inhabited by lazy and socially passive mediocrities with free gadgets in their hands.

In our opinion, workers released as a result of digitalization, who will receive the opportunity to constantly receive property support from the state, will begin to get used to this kind of constant provision and, as a result, a significant part of them are steadily degrading, becoming dependents. If we take the experience of past centuries as an example, then we can see that social dependency in all forms of its manifestation has always posed a huge threat to states, often entire civilizations perished from it. In this regard, it would be more correct to raise the question of the minimum social security for the released workers and their families. For those of them, who will still be of working age for a relatively long time, this support should be limited to a few years in order to enable them to master a new profession that is in demand on the market.

The primary task of the state is to ensure the smoothest transition possible for specific citizens who are losing their jobs. The state must act proactively. Otherwise, we will see an unprecedented rise in social tension. First of all, we should talk about the thoughtful policy of the state for the development of new and transformation of old sectors of the economy and the corresponding creation of new high-tech jobs. 
It should be understood that real life can significantly complicate the solution of the problem of compensation for laid off workers. The fact is that an attempt to introduce a tax on robotization can bring more tangible losses to humanity than we imagine. Yes, specific workers displaced from their jobs by robots will suffer. But workers in general may even benefit from the introduction of robots: labor productivity will rise, the cost of goods and services will fall, and prices will fall, increasing the purchasing power of wages.

The dilemma of modern development: either the acquisition of a society of knowledge and freedom of the spirit, or a consumer society, "addicted to numbers." Today, modern technologies have already enslaved people in many ways, opening up the prospect of unlimited consumption, comfort and entertainment, on the one hand, and total control over people, managing them, on the other. Under such conditions, how can a person return to himself, to humanizing nature? To practically rebuild a world in which a person will not be a stranger among strangers, but will feel like one of his own among his own?

\section{Conclusion}

The rapid development of digital civilization can turn into an uncontrolled process with unpredictable negative consequences for society. And we must understand what we are ready to pay for such drastic changes and which of them we accept and which are not. In these conditions, the regulatory function of professionals is required, who, on the basis of a careful and systematic study of pressing problems, are able to take preventive measures and painlessly fit society into the context of the new economic reality. With the development of the digital economy, the rapid development of existing and the formation of new institutions is required. The proper and timely development of social institutions that are adequate to the demands of the digital economy is an urgent need. We are talking about both formal and informal institutions, such as norms of behavior, assessment criteria, morality. However, in the current environment, stakeholders and beneficiaries with great market power are putting strong pressure on the quality of these new institutions. Among these qualities, first of all, is human orientation.

We see that the issues raised in the article today have become very relevant for many developed countries. It is also obvious that effective ways to solve the above problems are critically small in order for individual countries and the world community as a whole to be able to calmly look into the social future of the developing digital economy. Moreover, many countries, including Russia, do not see any special social threats for themselves from digitalization and robotization of production. The Russian government, for example, does not see the risks of an increase in unemployment due to the digitalization of the economy. This was announced by First Deputy Prime Minister, Finance Minister Anton Siluanov, speaking at the VTB Capital forum "Russia Calls". He said, that in other countries there is also a technological breakthrough, where unemployment is not due to liberation, and absolutely not have any fears to get social negative. Perhaps this view is due to the fact that our country is still significantly lagging behind developed countries in the development of the digital economy (due to an insufficiently favorable environment for innovation, including in the field of legal regulation, a low percentage of investments in technology and science, low level of use of digital technologies by business structures).

Nevertheless, the facts presented in this article indicate the opposite - the release of a significant mass of workers and the accompanying unemployment are an objective reality of the digitalization of the economy. Moreover, due to the unevenness of digitalization processes in countries with different levels of technological development, new social threats may arise. For example, a significant flow of skilled human capital freed up as a result of digitalization from more developed countries to less developed ones can cause social conflicts due to competition for jobs with local workers.

It is important to understand, that digitalization and robotization is not a utopia, but the harsh reality of the near future, and no measures to mitigate the blow to the workforce will help. The state should be proactive in developing appropriate compensatory mechanisms. Otherwise, we will see an unprecedented increase in social tension associated with the development of information technology in the economy and society.

\section{References}

[1] Workforce of the future: The competing forces shaping 2030 https://www.pwc.com/gx/en/services/people-organisation/workforce-of-the-future/ workforce-of-the-future-the-competing-forces-shaping-2030-pwc.pdf

[2] World Economic Forum, Digital Transformation Initiative. Unlocking \$ 100 Trillion for Business and Society from Digital Transformation. Executive Summary, January 2017, page 22. 
[3] Tritsch JL. Rise of the Robots: Technology and the Threat of a Jobless Future, by Martin Ford. Organization Management Journal, 2016, 13(2): 115-117.

https://doi.org/10.1080/15416518.2016.1180076

[4] Atkinson RD. In Defence of Robots. National Review, April 17, 2017.

http://www.nationalreview.com/article/446933/robots-jobs-industrial-future

[5] No. 64, Kommersant, April 13, 2017.

[6] Osipov V. The problem of employment in the digital economy. CITISE, 1(18), 2019.

[7] Conzalenko P. Cars without drivers: how technology will change the world economy in the next 15 years. Transport, May 23, 2015.

https://vc.ru/transport/8324-autonomous-cars

[8] Space tractor. How can an unmanned combine walk in the field with an accuracy of up to $3 \mathrm{~cm}$, August $29,2019$. https://tass.ru/ekonomika/6799945

[9] Richard Florida: Creative class: people who change the future. Classic XXI, 2007.

[10] Bourdieu P. Sociology of politics. Translated from French: Collection of articles, 1993.

[11] Voznesenskaya ED. Sociology of politics. Digest of articles, 1993.

[12] Guy Standing "Precarity: The New Dangerous Class". Ad Marginem, 2014 